\title{
Maximum opening of the mouth by mouth prop during dental procedures increases the risk of upper airway constriction
}

This article was published in the following Dove Press journal:

Therapeutics and Clinical Risk Management

II May 2010

Number of times this article has been viewed

\author{
Hiroshi Ito' \\ Hiroyoshi Kawaai' \\ Shinya Yamazaki' \\ Yosuke Suzuki² \\ 'Division of Systemic Management, \\ Department of Oral Function, \\ ${ }^{2}$ Division of Radiology and Diagnosis, \\ Department of Medical Sciences, \\ Ohu University, Post Graduate \\ School of Dentistry, Koriyama City, \\ Fukushima Prefecture, Japan
}

\begin{abstract}
From a retrospective evaluation of data on accidents and deaths during dental procedures, it has been shown that several patients who refused dental treatment died of asphyxia during dental procedures. We speculated that forcible maximum opening of the mouth by using a mouth prop triggers this asphyxia by affecting the upper airway. Therefore, we assessed the morphological changes of the upper airway following maximal opening of the mouth. In 13 healthy adult volunteers, the sagittal diameter of the upper airway on lateral cephalogram was measured between the two conditions; closed mouth and maximally open mouth. The dyspnea in each state was evaluated by a visual analog scale. In one subject, a computed tomograph (CT) was taken to assess the three-dimensional changes in the upper airway. A significant difference was detected in the mean sagittal diameter of the upper airway following use of the prop (closed mouth: $18.5 \pm 3.8 \mathrm{~mm}$, maximally open mouth: $10.4 \pm 3.0 \mathrm{~mm}$ ). All subjects indicated upper airway constriction and significant dyspnea when their mouth was maximally open. Although a CT scan indicated upper airway constriction when the mouth was maximally open, muscular compensation was admitted. Our results further indicate that the maximal opening of the mouth narrows the upper airway diameter and leads to dyspnea. The use of a prop for the patient who has communication problems or poor neuromuscular function can lead to asphyxia. When the prop is used for patient refusal in dentistry, the respiratory condition should be monitored strictly, and it should be kept in mind that the "sniffing position" is effective for avoiding upper airway constriction. Practitioners should therefore consider applying not only systematic desensitization, but also general anesthesia to the patient who refuses treatment, because the safety of general anesthesia has advanced, and general anesthesia may be safer than the use of a prop and restraints.
\end{abstract}

Keywords: mouth prop, dental procedure, upper airway constriction, asphyxia, maximum opening of the mouth, risk management

\section{Introduction}

The number of cases of accidental death or shock associated with dental procedures was investigated from 1950 to 2004 in Japan. ${ }^{1}$ The deaths of 126 patients in 200 cases of accidents were reported. The main causes of death were acute cardiac failure $(24 \%)$ and asphyxia (21\%). Asphyxia most frequently occurred in healthy children or mentallydisabled patients undergoing a dental procedure with a mouth prop and body restrainer. It has been reported that percutaneous arterial oxygen saturation $\left(\mathrm{SpO}_{2}\right)$ decreases significantly when patients are treated while having a mouth prop and body restrainer in place. ${ }^{2}$ However, the underlying cause is of the increased risk of asphyxia in these situations is not clear. Therefore, it is necessary to clarify the cause of such accidents in order to prevent them from occurring in the future. We speculated that the maximum opening of the
Correspondence: Hiroshi Ito Division of Systemic Management, Department of Oral Function, Ohu University, Postgraduate School of Dentistry, 3I-I Misumido Tomita Koriyama, Fukushima, 963-86II Japan Tel +8I 249329337

Fax +81 249389192

Email h-itou@den.ohu-u.ac.jp 
mouth by use of a mouth prop results in morphologic changes around the upper airway. To assess this possibility, the influence of maximal opening of the mouth using a mouth prop on airway morphology was investigated statistically using Wilcoxon $t$-test, Chi-square test, and Spearman rank-correlation analysis from cephalometric evaluations.

\section{Subjects and methods}

After approval of the ethical review board of Ohu university, 13 healthy adult volunteers (age: $33.0 \pm 9.8$ years, height: $170.8 \pm 6.5 \mathrm{~cm}$, body weight: $72.0 \pm 6.5 \mathrm{~kg}$ ) (Table 1) who consented for this study participated as the subjects. Due to ethical concerns about using students or patients as subjects (because this study used X-rays), 13 staff members of our hospital participated voluntarily in this study. All subjects were kept under two conditions (closed mouth and the maximally open mouth as a result of the use of a mouth prop) in supine position for 30 seconds. Lateral cephalograms were taken under each condition. During each condition, the patient's $\mathrm{SpO}_{2}(\%)$ was measured, and their extent of dyspnea was evaluated by using a visual analog scale $($ VAS $)(0 \mathrm{~mm}=$ no dyspnea, $100 \mathrm{~mm}=$ unbearable dyspnea). KXO-50F (Toshiba, Tokyo, Japan) was used as an $\mathrm{X}$-ray generator, and the conditions of the X-rays used for this study are shown in Table 2 . The universal mouth prop (Oyama Dental Industrials, Tokyo, Japan) was used to keep the mouth maximally open. The measurement points on the lateral cephalogram in this study are shown in Figure 1. These measurement points were based on a study that evaluated the upper airway constriction after orthognathic surgery. ${ }^{3}$ Under each condition, the three intervals in the sagittal diameter of the upper airway at the uvular tip (A), at the midpoint between the 2 nd and 3 rd cervical vertebra as a tongue base (B), and at the epiglottic vallecula (C), were traced and measured from the measurement points on the lateral cephalogram. Then the average of $\mathrm{A}, \mathrm{B}$, and $\mathrm{C}$ was assumed as the mean upper airway diameter. In addition, the inter-cusp interval from the upper to lower incisor was traced and measured in each condition. To minimize the

Table I Characteristics of the study subjects

\begin{tabular}{ll}
\hline Number & 13 \\
Gender & Male \\
Age $(\mathrm{yr})$ & $33.0 \pm 9.8$ \\
Height $(\mathrm{cm})$ & $170.8 \pm 6.5$ \\
Weight $(\mathrm{kg})$ & $72.0 \pm 8.6$ \\
ASA-PS & $\mathrm{I}$ \\
\hline
\end{tabular}

Abbreviation: ASA-PS, American Society of Anesthesiologists-physical status.
Table 2 Conditions of lateral cephalometric radiography

\begin{tabular}{ll}
\hline X-ray tube voltage/current & $95 \mathrm{kV} / 200 \mathrm{~mA}$ \\
Exposure time & $0.01 \mathrm{sec}$ \\
Radiographic grid & $6: 1$ \\
$\begin{array}{l}\text { Distance from X-ray generator } \\
\text { to film }\end{array}$ & $140 \mathrm{~cm}$ \\
$\begin{array}{l}\text { Distance from X-ray generator } \\
\text { to midline of head }\end{array}$ & $125 \mathrm{~cm}$ \\
Head position & $\mathrm{FH}$ plane and basic plane cross \\
& at right angle \\
Center point of exposure & Intersecting point between \\
axis & horizontal line of porus acusticus \\
& and vertical line of mentum \\
\hline
\end{tabular}

Abbreviation: FH plane, Frankfort horizontal plane.

technical errors, each dataset was adopted from the average value of tracing made by three different researchers who was calibrated previously.

Statistical analysis was performed by Wilcoxon $t$-test and $2 \times 2$ Chi-square test, and $P<0.05$ was considered as statistically significant. In addition, Spearman rank-correlation analysis was applied to confirm the correlation between the constriction rate (\%) in the mean upper airway diameter and the body mass index (BMI) [body weight $(\mathrm{kg}) /$ height $(\mathrm{m})^{2}$ ] as an obesity index, the inter-cusp interval ( $\mathrm{mm}$ ) from upper to lower incisor in maximum opening, or the VAS (mm) of dyspnea.

In one subject, head-neck X-ray computed tomography (CT) was used to assess the three-dimensional changes around the upper airway space in each condition. Only one subject was used for X-ray CT due to ethical considerations because the radiation exposure dose was larger than cephalogram. However, the morphological findings of the head-neck X-ray CT were interpreted by the department of oral anatomy.

\section{Results}

The results of the lateral cephalograms of the 13 subjects are shown in Figure 2, and all results of measurements are shown in Table 3. The inter-cusp interval from the upper to lower incisor when the mouth was maximally open was $57.5 \pm 8.5 \mathrm{~mm}$. In the sagittal diameter of the upper airway of the 13 subjects, A was $16.1 \pm 3.0 \mathrm{~mm}$, B was $14.6 \pm 3.8 \mathrm{~mm}$, and $C$ was $24.7 \pm 5.7 \mathrm{~mm}$ in the closed mouth condition. However, A decreased to $7.4 \pm 3.1 \mathrm{~mm}$, B decreased to $7.7 \pm 3.0 \mathrm{~mm}$ and $\mathrm{C}$ decreased to $16.3 \pm 5.2 \mathrm{~mm}$, when the mouth was in the maximally open position. These decreases were observed in all subjects (Figure 3), and the decreases resulted in significant $(P=0.0016)$ decreases in the mean upper airway diameter (Closed mouth: $18.5 \pm 3.8 \mathrm{~mm}$, 


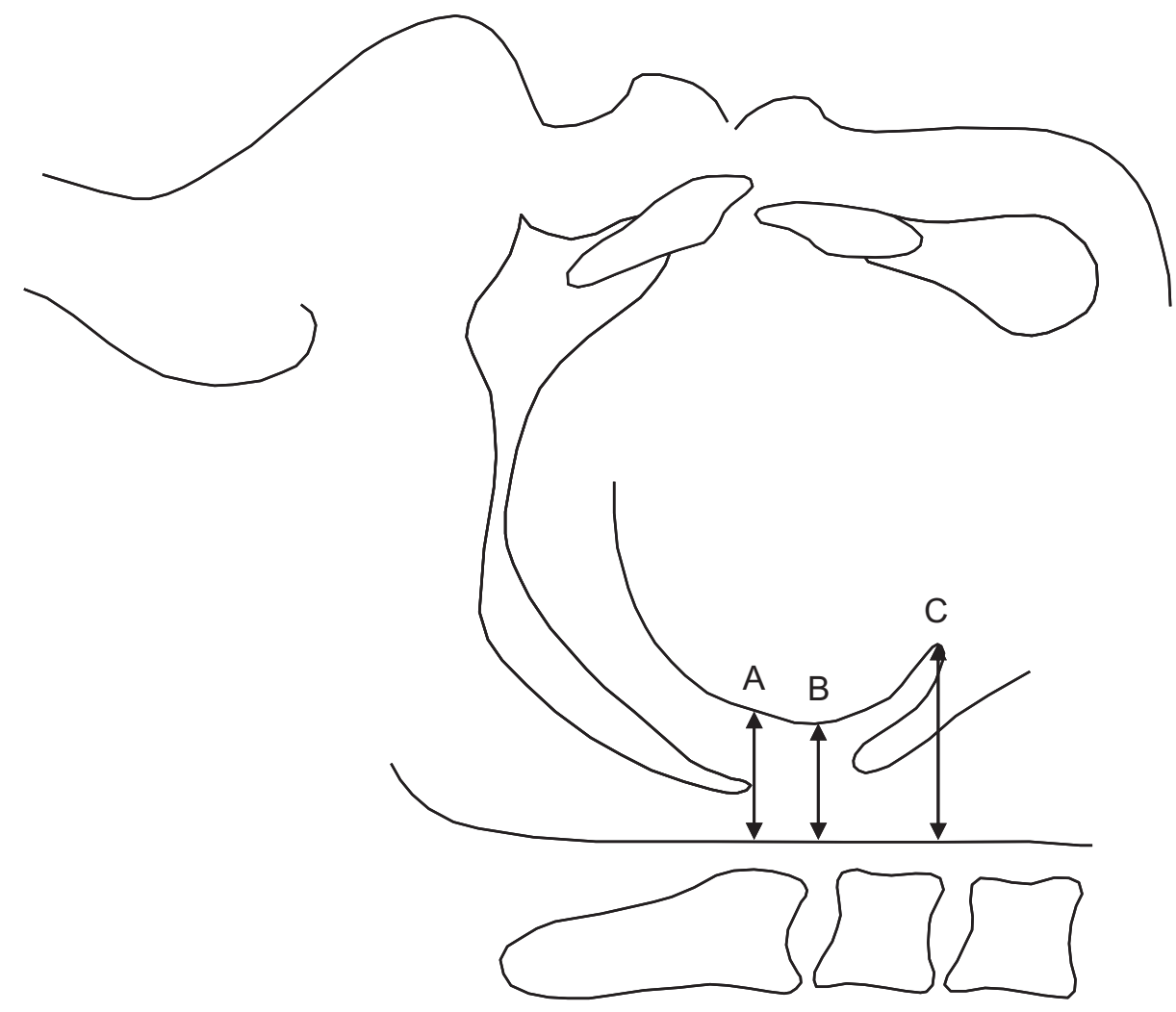

Figure I Measurement points in the upper airway on the lateral cephalogram. Three intervals in the sagittal diameter of upper airway at; A) Uvular tip. B) Midpoint between the 2 nd and 3 rd cervical vertebra as a tongue base. C) Epiglottic vallecula.

Maximally open mouth: $10.4 \pm 3.0 \mathrm{~mm})$. Mesurements $\mathrm{A}, \mathrm{B}$, and $\mathrm{C}$ were constricted by $54.1 \%, 47.3 \%$, and $47.4 \%$, respectively. There is little difference in the constriction rate between these three points (Figure 4).

The VAS of the dyspnea was $0 \pm 0 \mathrm{~mm}$ in the closed mouth position, but increased to $48.5 \pm 22.2 \mathrm{~mm}$ when the subject had a maximally open mouth. In addition, the subjects' sensation of dyspnea increased significantly $(P=0.0016)$. There were no significant differences in oxygenation, with the average $\mathrm{SpO}_{2}$ being $97.6 \pm 0.9 \%$ in the closed mouth position, and $97.2 \pm 0.8 \%$ when the subjects were in the maximally open mouth position (Figure 5). Moreover, there was no significant correlation between the constriction rate in the mean upper airway diameter and the BMI as obesity index, or the inter-cusp interval from the upper to the lower incisors during maximum opening. However, a positive correlation $(P=0.0000014)$ was detected between the constriction rate in the mean upper airway diameter and the VAS of dyspnea (Figure 6).

Although the head-neck X-ray CT also indicated that upper airway constriction was induced by maximum opening of the mouth, the finding of superior pharyngeal muscle constriction was observed to keep the upper airway diameter (Figure 7).

\section{Discussion}

It has previously been reported that the airway diameter decreases after mandibular setback surgery for mandibular prognathism, ${ }^{3-5}$ and the airway diameter increases after the use of mandibular traction or after patients wear a mandibular advancement device (MAD) as oral application for the treatment of sleep apnea syndrome. ${ }^{6-8}$ However, there have not been any previous reports about the influence of mouth position on upper airway shape and function. To investigate whether mouth position during dental procedures affects the upper airway, we used a mouth prop to enforce maximum mouth opening, then investigated the effects on the airway via cephalometric evaluation.

According to an investigation of the causes of death associated with dental procedures, asphyxia had occurred most often when the pediatric patients or mentally-disabled patients with strong treatment refusal were treated using a mouth prop and body restrainer. For such patients, we tend to use the mouth prop under maximum opening, because it is easier to remove the mouth prop. Therefore, to determine whether there was a link between the use of a mouth prop and airway constricture (possibly leading to asphyxia), the changes in the upper airway induced 


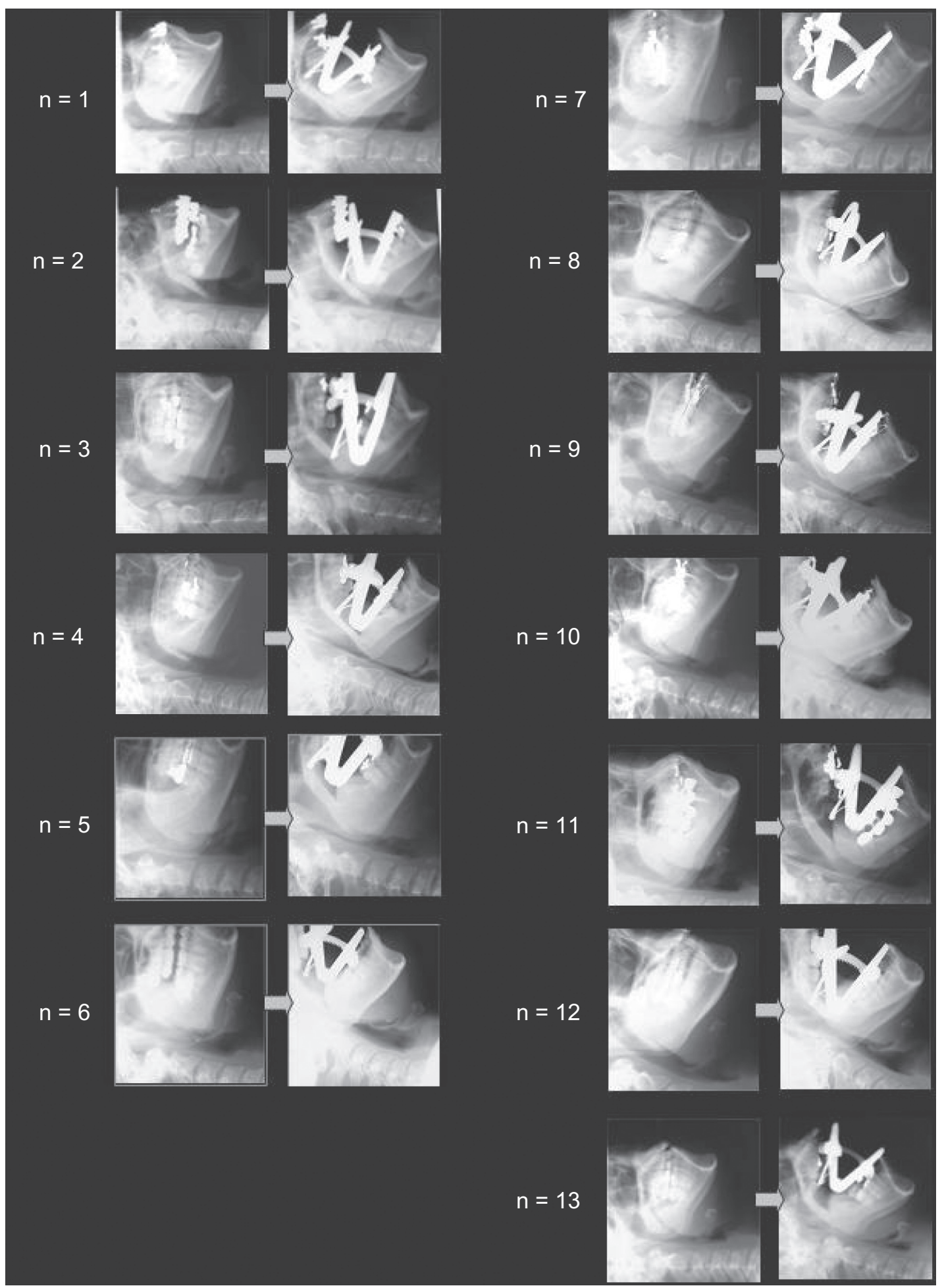

Figure 2 Individual cephalograms for each patient. All subjects indicated upper airway constriction by maximum opening of the mouth.

by maximum opening of the mouth by a mouth prop was investigated in this study.

From this result, we concluded that when the mouth is maximally open while the subject is maintained in the supine position, the mean upper airway diameter decreased to approximately half. We speculate that the tongue base, muscle, and soft tissue around the pharynx were physically pushed toward the posterior wall of the pharynx by the opened mandible, thus reducing the airway diameter. This suggests that keeping the mouth maximally open by 


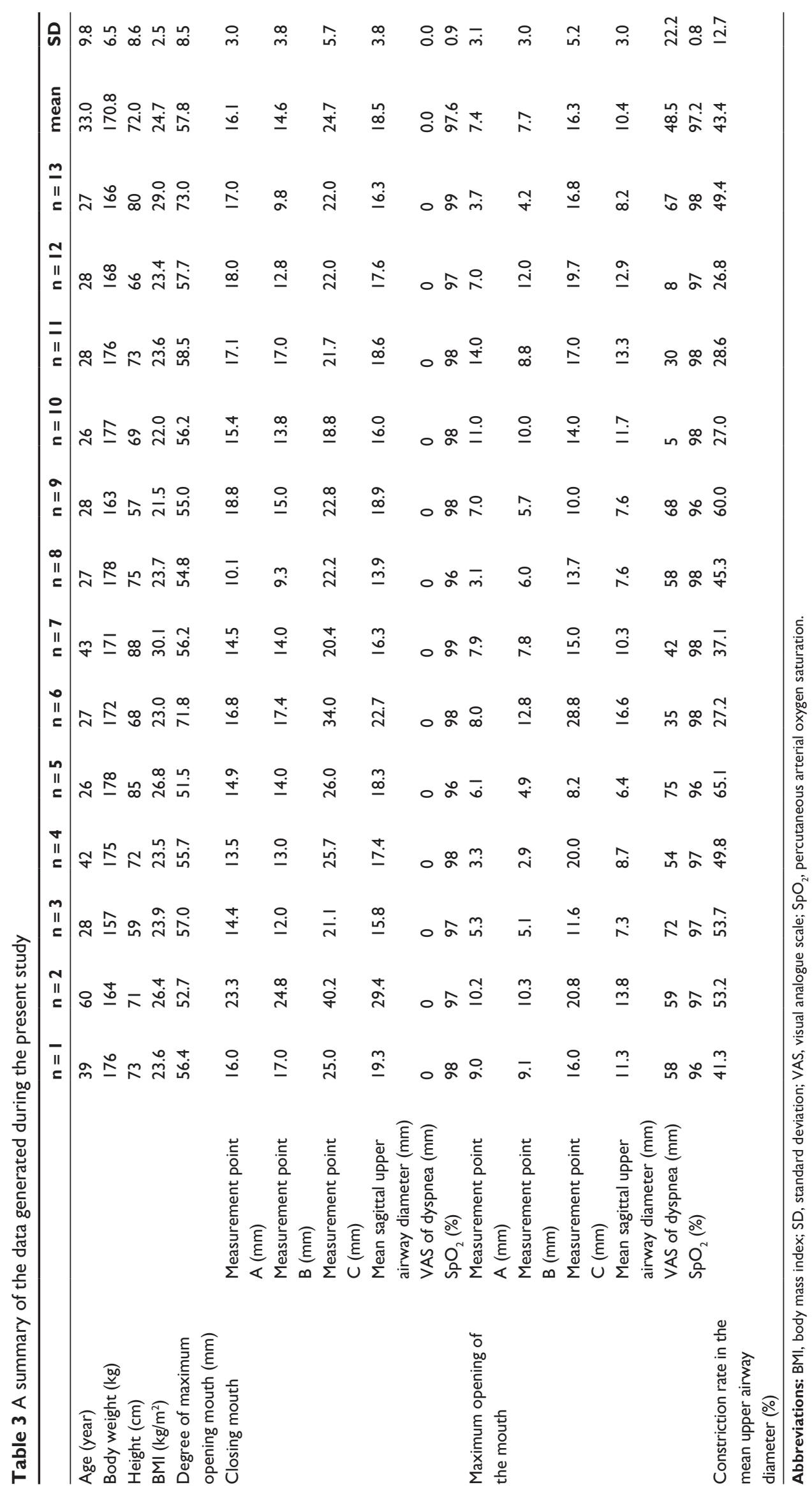


Change of measurement point $A$

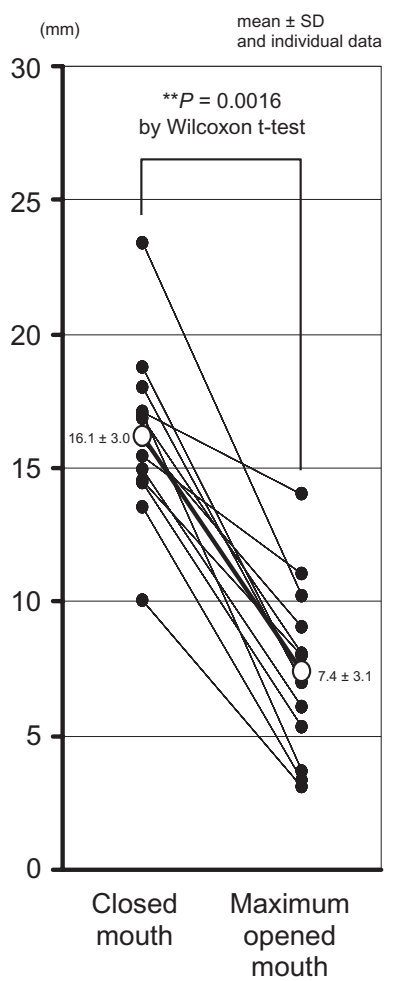

Change of measurement point $B$

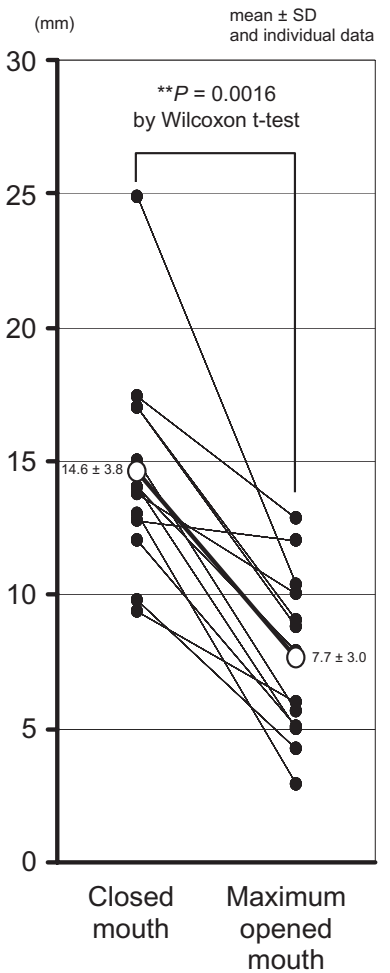

Change of measurement point $\mathrm{C}$

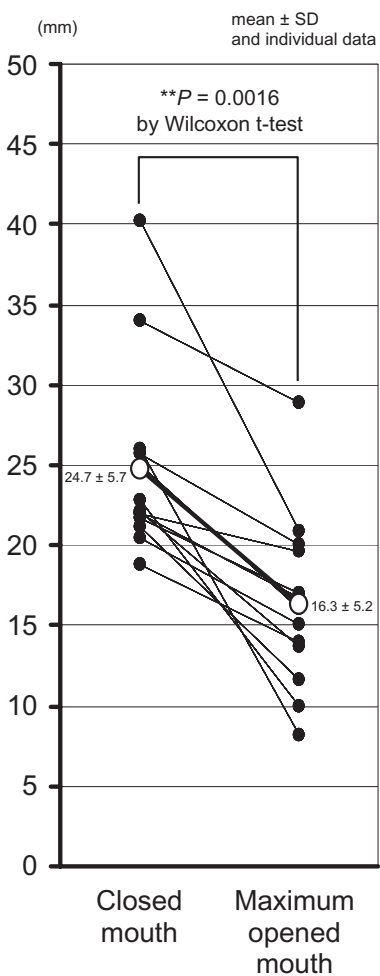

Change of mean airway diameter

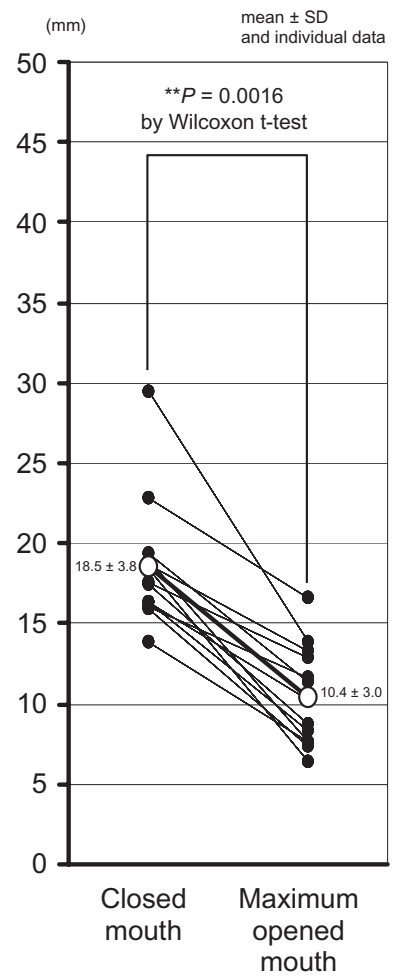

Figure 3 Decreases in the sagittal upper airway diameter induced by maximum opening of the mouth.

mouth prop for dental procedures might lead to airway constriction.

Although we did not observe any significant change in the $\mathrm{SpO}_{2}$ in our subjects, we did observe significant dyspnea in all subjects. However, all of our study subjects were healthy adults, and they were kept in the maximally open mouth position for only 30 seconds.

The upper airway, which includes the nasal cavity, pharynx and larynx, has several functions (heating, humidifying and filtering air, as well as regulating swallowing and speech). ${ }^{9}$ The diameter and compliance of the upper airway are adjusted according to the situation. When negative pressure is provided in the upper airway, the airway patency reflex works to dilate the airway by activating the surrounding muscles. ${ }^{10}$ It has thus been suggested that the upper airway rarely constricts under the conscious state. ${ }^{11}$ In fact, our finding of pharyngeal muscle contraction in the head-neck X-ray $\mathrm{CT}$ is regarded as occurring to compensate for the effects of the mouth prop and to help resist the upper airway constriction. It would appear that this compensatory response is mediated by the superior pharyngeal constrictor muscle and the pharyngeal plexus, which consists of the glossopharyngeus, vagus, and accessory nerves, which control the superior pharyngeal constrictor muscle. Therefore, it should be examined more whether the compensatory response is dysfunctional in pediatric patients, disabled patients, myopathic patients, and the patients who are taking psychoactive and/or sedative drugs that impair the neuromuscular function.

In this study, no significant correlation was found between the constriction rate in the mean upper airway diameter and the BMI, or the degree of maximum opening of the mouth. Therefore, the probability of upper airway constriction by mouth prop does not depend on the degree of obesity or the maximum opening mouth. It appears that the upper airway constriction depends primarily on the pharyngeal neuromuscular function. On the other hand, a correlation was detected between the constriction rate in the mean upper airway diameter and the VAS of dyspnea. This suggests that the feeling of dyspnea progresses as the constriction rate in the upper airway increases. This indicates that special attention should be paid to patient complaints of dyspnea in order to prevent further hypoxia. ${ }^{12,13}$

In this study, the data were taken under the supine position, because most of usual dental procedures are administered with patients in the supine position. Compared to the seated position, in the supine position, the diaphragm is displaced toward the head by abdominal pressure. Then, a decrease in thoracic compliance results in a decrease 

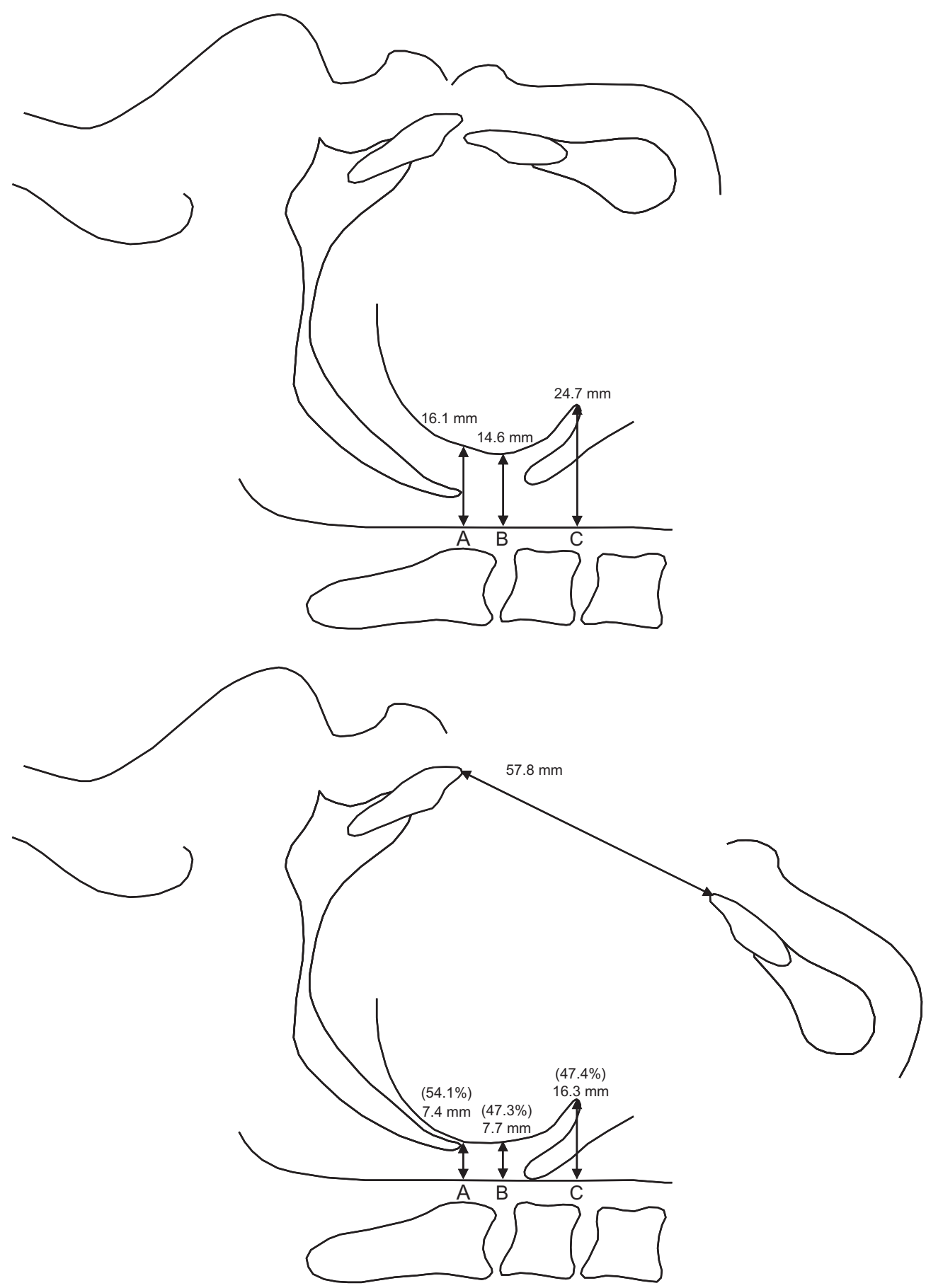

Figure 4 Changes in the upper airway formation induced by maximum opening of the mouth.

of functional residual capacity. ${ }^{14}$ Additional use of body restraints further impairs respiratory function, and $\mathrm{SpO}_{2}$ has been demonstrated to decrease significantly when pediatric patients were treated under body restraint. ${ }^{2}$ In this study, keeping the mouth at its maximum open position using a mouth prop for 30 seconds induced dyspnea even without use of body restraints. Therefore, it should be confirmed whether the combined use of a mouth prop and body restraints amplifies the risk or not.
Pediatric subjects were excluded from this study for ethical considerations. However, anatomically, children have relatively large tongues and short necks in comparison with adults. ${ }^{15}$ And, the primitive pharyngeal reflex is inhibited by microgenia, sleep apnea syndrome, taking psychoactive or sedative drugs, and hypertrophy of the adenoids, tonsils, and tongue. ${ }^{16}$ Furthermore, it has been reported that the arterial oxygen saturation decreased significantly by bite block for dental procedure in the handicapped patients. ${ }^{13}$ 
Change of dyspnea by VAS

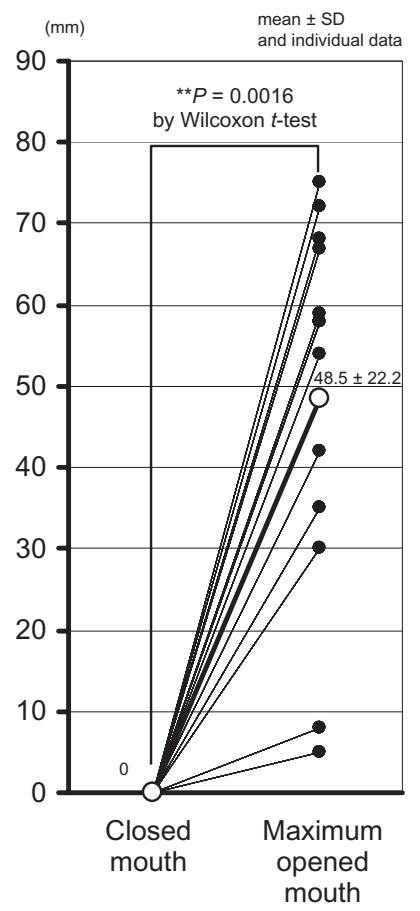

Change of $\mathrm{SpO}_{2}$

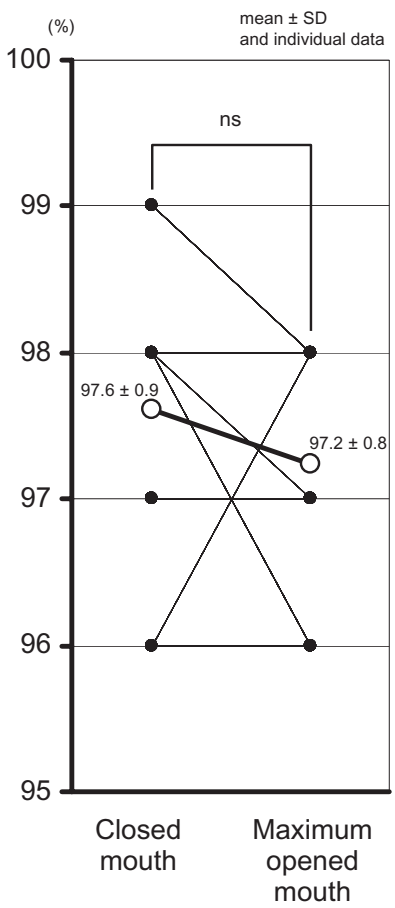

Figure 5 Changes of dyspnea and $\mathrm{SpO}_{2}$ induced by maximum opening of the mouth.

Abbreviations: SD, standard deviation; $\mathrm{SpO}_{2}$, percutaneous arterial oxygen saturation; VAS, visual analog scale.

Systematic desensitization therapy is often successful, making the use of a mouth prop and/or body restraints unnecessary. ${ }^{17,18}$ However, when the mouth prop must be used during a dental procedure, the patient's respiratory condition should be carefully monitored. In particular, a pulse-oxymeter is effective for detecting hypoxia at an early stage. ${ }^{2,19,20}$ To ensure better dilation of the upper airway in the supine position, the so-called "sniffing position" which keeps elevation in both the forehead and chin using a thick pillow is effective. ${ }^{21}$ Such a position is recommended when patients must be treated using a mouth prop.

Recently, intubated general anesthesia has become safer than before, as dramatic progress in drugs, monitoring, equipment, and technology has been made. From the 1950s to the 1990 s, the mortality caused by general anesthesia plummeted from $1 / 2,860$ to $1 / 400,000$ respectively. ${ }^{22,23}$ The mortality caused by local anesthesia is approximately 7 times higher than that caused by general anesthesia. ${ }^{24}$

\section{Conclusions}

The influence of maximum opening of the mouth using a mouth prop on the upper airway was investigated from lateral cephalograms of patients in control (closed mouth) and prop-induced open-mouthed positions. We made several observations:
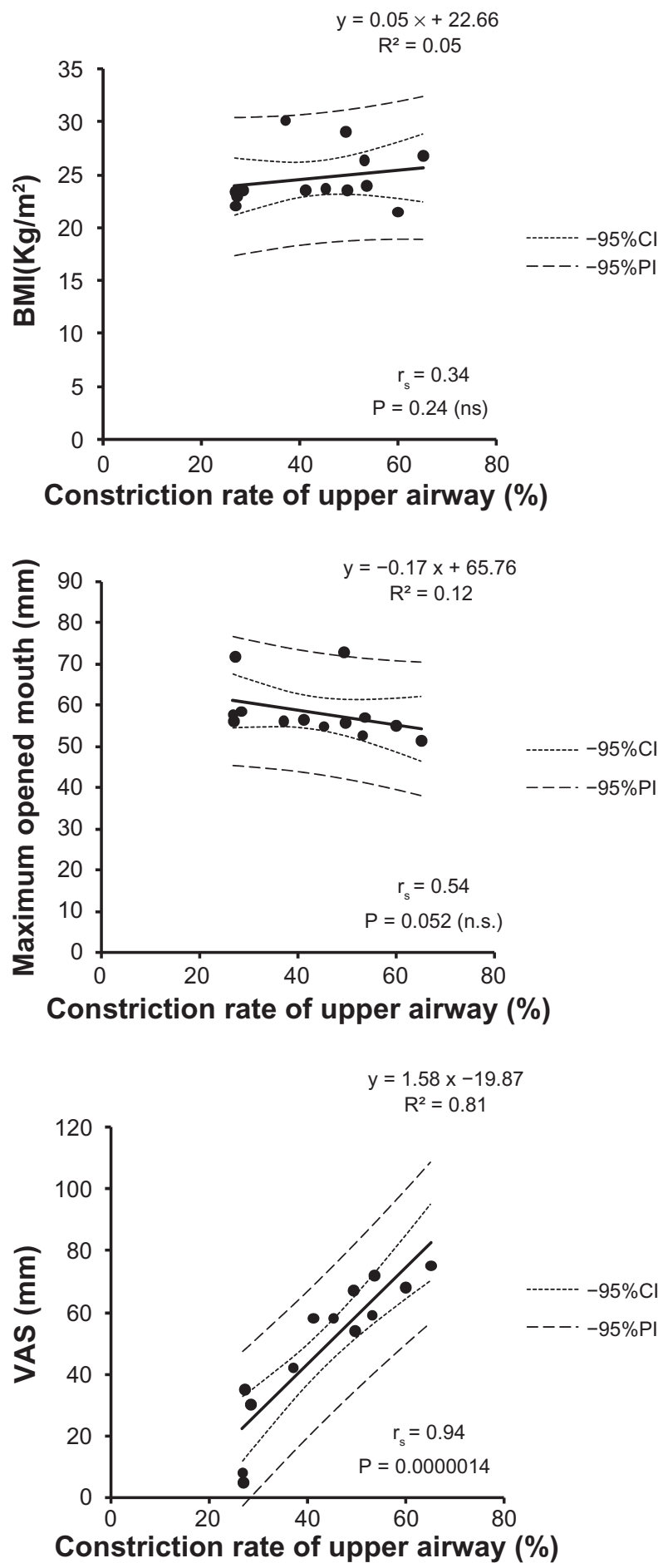

Figure 6 Correlation between the constriction rate (\%) in the mean upper airway diameter and BMI $\left(\mathrm{kg} / \mathrm{m}^{2}\right)$, maximum opening of the mouth $(\mathrm{mm})$, or VAS $(\mathrm{mm})$. Abbreviations: $\mathrm{BMI}$, body mass index; $\mathrm{Cl}$, confidence interval; $\mathrm{Pl}$, probability interval; VAS, visual analog scale.

1. The mean upper airway diameter decreased to approximately half following maximum opening of the mouth using a mouth prop, and subjects reported feeling significant dyspnea.

2. The maximum opening of the mouth for 30 seconds did not change the $\mathrm{SpO}_{2}$, however, the subjects reported feeling significant dyspnea. 


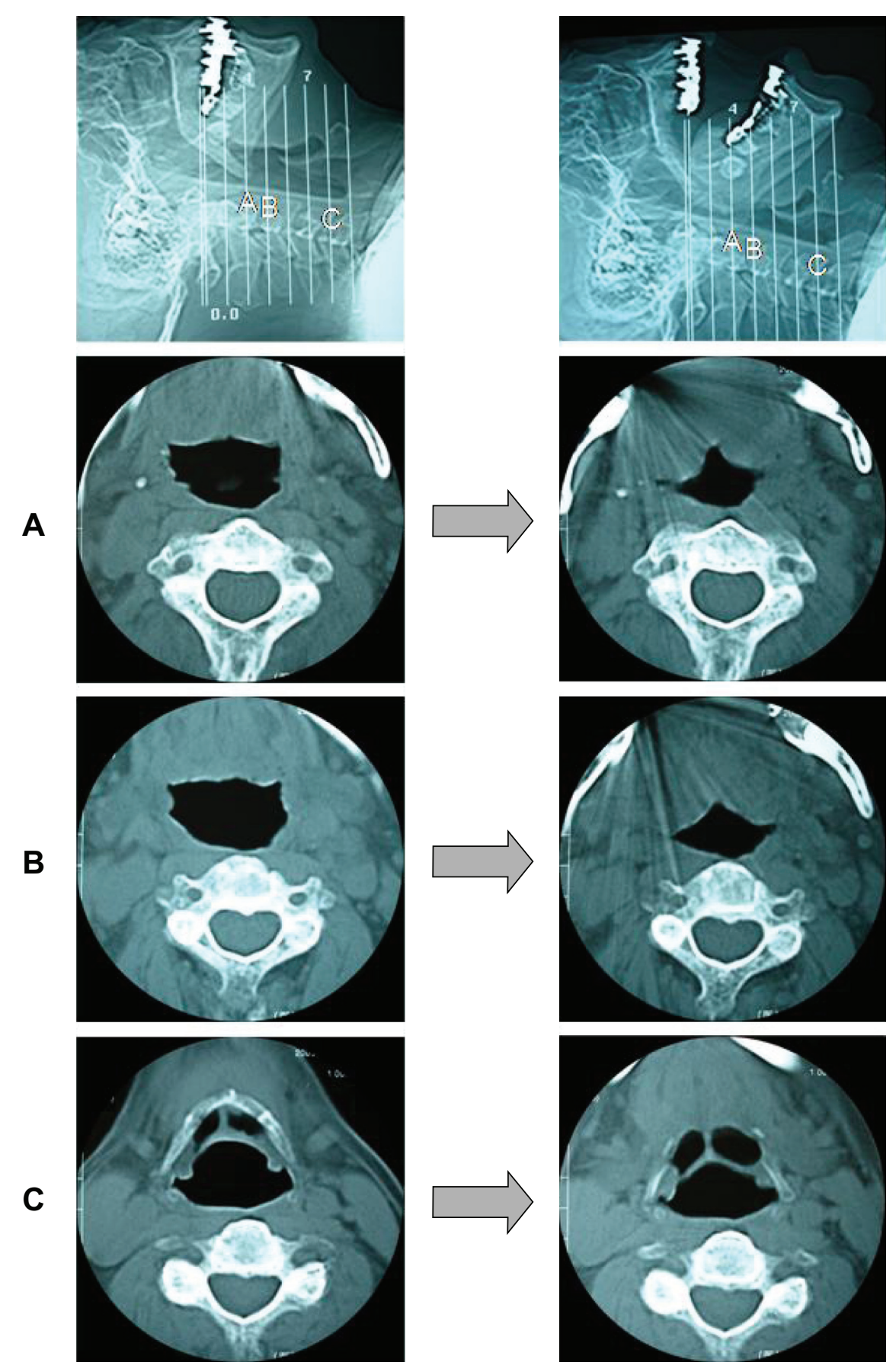

Figure 7 Difference in the airway between the closed mouth and the maximally open mouth. This X-ray computed tomograph (CT) also indicated that the upper airway became narrower when the mouth is maximally open.

3. In the head-neck X-ray CT, upper airway muscle contraction was observed to serve as a compensatory mechanisms to maintain the proper upper airway diameter. This muscle contraction is likely controlled by the superior pharyngeal constrictor muscle and pharyngeal plexus.

\section{Disclosures}

The authors report no conflicts of interest in this work.

\section{References}

1. Ito H, Ogawa S, Seino H, et al. An analysis of 200 cases of severe shock and cardiopulmonary arrest that were related with dental treatment or oral surgery. Japanese Journal of Reanimatology. 2005;24(2):82-87.

2. Shimamura K, Haruyama H, Aizawa N, et al. Fluctuations in the pulse rate and $\mathrm{SpO}_{2}$ during dental treatment of the children under restraint. Japanese Journal of Pediatric Dentistry. 2005;43(5):613-618.

3. Terakado K, Shiina Y, Naruse T, et al. Effects of surgical orthodontic treatment on oral cavity, tongue, and pharyngeal airway (Part 1: Changes caused by mandibular setback surgery). Shika Gakuh. 1997;97(2):181-191. 
4. Degerliyurt K, Ukei K, Hashiba Y, et al. The effect of mandibular setback or two-jaws surgery on pharyngeal airway among different genders. Int J Oral Maxillofac Sur. 2009;38(6):647-652.

5. Hwang S, Chung CJ, Choi YJ, et al. Changes of hyoid, tongue and pharyngeal airway after mandibular setback surgery by intraoral vertical ramus osteotomy. Angle Orthod. 2010;80(2):302-308.

6. Pradel W, Lauer G, Dinger J, et al. Mandibuler traction - an alternative treatment in infants with Pierre Robin sequence -. J Oral Maxillofac Surg. 2009;67(10):2232-2237.

7. Lee $\mathrm{CH}, \mathrm{Kim} \mathrm{JW}$, Lee HJ, et al. An investigation of upper airway changes associated with mandibular advancement device using sleep videofluoroscopy in patients with obstructive sleep apnea. Arch Otolaryngol Head Neck Surg. 2009;135(9):910-914.

8. Doff MH, Hoekema A, Pruim GJ, et al. Effects of a mandibular advancement device on the upper airway morphology: a cephalometric analysis. J Oral Rehabil. 2009;36:330-337.

9. Pierce RJ, Worsnop CJ. Upper airway function and dysfunction in respiration. Clin Exp Pharmacol Physiol. 2009;26(1):1-10.

10. Thach BT. Neuromuscular control of upper airway patency. Clin Perinatol. 1992;19(4):773-788.

11. Isono S, Nishino T. Airway protective reflexes and mechanisms of airway maintenance. Kokyu To Junkan. 1998;46(5): 469-475.

12. Hagberg C, Georgi R, Krier C. Complications of managing the airway. Best Pract Res Clin Anaesthesiol. 2005;19(4):641-659.

13. Ogasawara T, Watanabe T, Hosaka K, et al. Hypoxemia due to inserting a bite block in severely handicapped patients. Spec Care Dentist. 1995;15(2):70-73.
14. Froese AB, BryanAC. Effects of anesthesia and paralysis on diaphragmatic mechanics in man. Anesthesiology. 1974;41(3):242-255.

15. Dickison AE. The normal and abnormal pediatric upper airway. Recognition and management of obstruction. Clin Chest Med. 1987;8(4):583-596.

16. Nishino $\mathrm{T}$, Tagaito $\mathrm{Y}$, Isono $\mathrm{S}$. Cough and other reflexs on irritation of airway mucosa in man. Pulm Pharmacol. 1996;9(5-6):285-292.

17. Golabek T. Systematic desensitization: a treatment for odontophobia. TIC. 1982;41(11):4-5.

18. Carlsson SG, Linde A, Berggren U, et al. Reduction of dental fear: psychophysiological correlates. Community Dent Oral Epidemiol. 1986;14(5):253-257.

19. Fukayama H, Yagiela JA. Monitoring of vital signs during dental care. Int Dent J. 2006;56(2):102-108.

20. Yamazaki S, Kawaai H, Sasaki S, et al. Availability of a remote online hemodynamic monitoring system during treatment in a private dental office for medically high-risk patients. Ther Clin Risk Manage. 2008;4(4):721-726.

21. Burwell DR, Jones JG. The airway and anesthesia. Pathophysiology. Anaesthesia. 1996;51(10):943-954.

22. Beecher HK, Todd DP. A study of deaths associated with anesthesia and surgery based on a study of 599, 548 anesthesias in ten institutions, 1948-1952 inclusive. Ann Surg. 1954;140(1):2-34.

23. Voelker R. Medical News and Perspectives; Anesthesia-related risk have plummeted. JAMA. 1995;273(6):445-446.

24. Olsson GL, Hallěn B. Cardiac arrest during anesthesia. A computeraided study in 250, 543 anaesthetics. Acta Anaesthesiol Scand. 1988;32(8):653-664.
Therapeutics and Clinical Risk Management

\section{Publish your work in this journal}

Therapeutics and Clinical Risk Management is an international, peerreviewed journal of clinical therapeutics and risk management, focusing on concise rapid reporting of clinical studies in all therapeutic areas outcomes, safety, and programs for the effective, safe, and sustained use of medicines. This journal is indexed on PubMed Central, CAS,

\section{Dovepress}

EMBase, Scopus and the Elsevier Bibliographic databases. The manuscript management system is completely online and includes a very quick and fair peer-review system, which is all easy to use. Visit http://www.dovepress.com/testimonials.php to read real quotes from published authors. 